\title{
Parental separation and adult psychological distress: evidence for the 'reduced effect' hypothesis?
}

\author{
Rebecca Lacey \\ International Centre for Life Course Studies in Society and Health, Dept. Epidemiology \& Public Health, \\ University College London \\ Rebecca.Lacey@ucl.ac.uk \\ Mel Bartley \\ International Centre for Life Course Studies in Society and Health, Dept. Epidemiology \& Public Health, \\ University College London \\ Hynek Pikhart \\ Dept. Epidemiology \& Public Health, University College London \\ Mai Stafford \\ MRC Unit for Lifelong Health and Ageing, London \\ Noriko Cable \\ International Centre for Life Course Studies in Society and Health, Dept. Epidemiology \& Public Health, \\ University College London
}

Lester Coleman

One Plus One Marriage and Relationship Research, London

\section{Abstract}

Parental separation has been linked to increased likelihood of reporting psychological distress in adulthood, but relatively little is known about how this association may have changed over time. One hypothesis is that as the experience of separation has become more common, the association with psychological distress will reduce (the 'reduced effect' hypothesis). Previous evidence using the British birth cohorts does not support this hypothesis, but past studies have several limitations which we aim to address. In this study we measure parental separation from birth, account for missing data and statistically test cohort differences using data from two British birth cohorts - the 1958 National Child Development Study (NCDS) and 1970 British Cohort Study (BCS). Despite these methodological improvements, we find little evidence to support the 'reduced effect' hypothesis: parental separation was associated with a similarly increased likelihood of reporting psychological distress in adulthood for men and women in both cohorts.

UK divorce rates have increased rapidly since the mid-20 ${ }^{\text {th }}$ century (fig. 1). This trend translates into an increasing probability that children will experience family disruption across this period. A longitudinal link between parental separation and adult psychological distress indicates that parental separation occurring during childhood is associated with increased reporting of psychological distress in adulthood (e.g. Chase-Lansdale, Cherlin \& Kiernan, 1995; Kendler, Shether, Garner, \& Prescott, 2002; Kuh \& Maclean, 1990; Rodgers, 1990; Rodgers \& Pryor, 1998). However the experience of parental separation may change 
Figure 1 - Trend in the number of divorces, England and Wales, 1946-2009

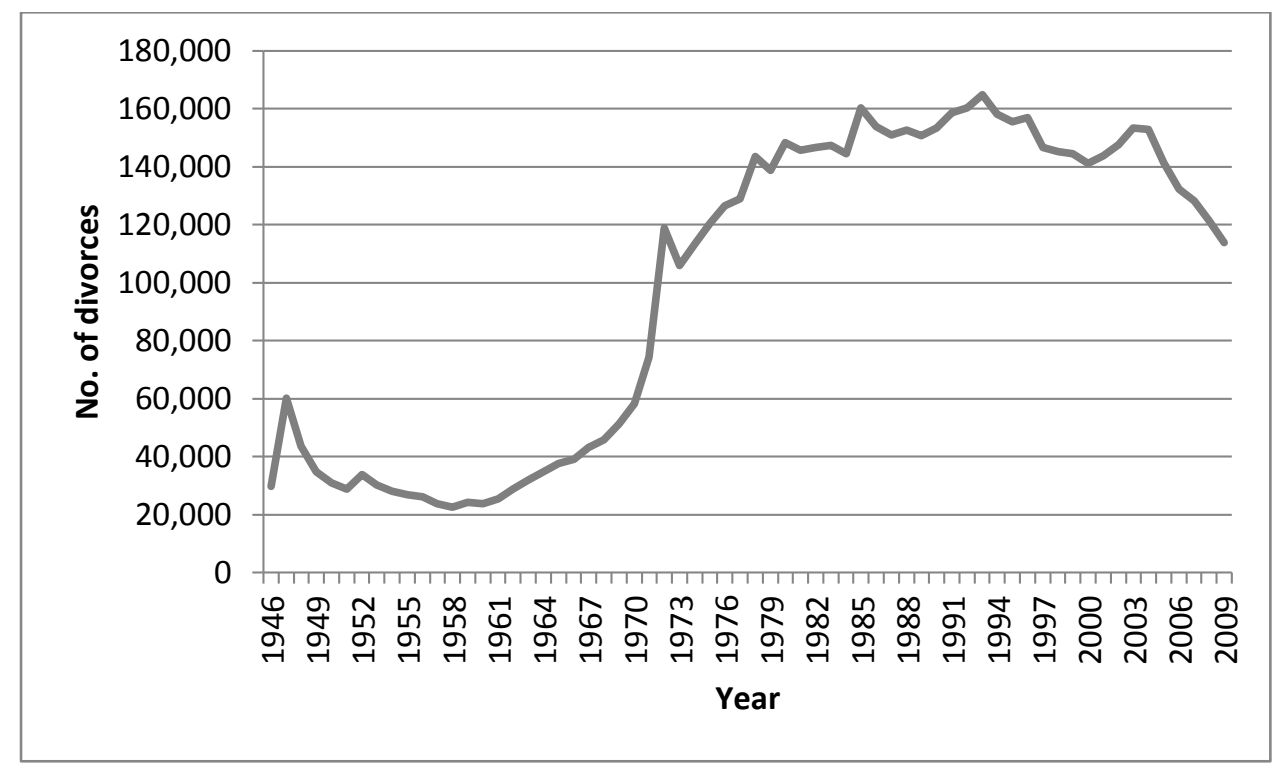

Source: Data taken from 'Divorces 1858-2003' (Office for National Statistics 2006); 'Marriage, divorce and adoption statistics. FM2 No 35' (ONS 2010)

over time because social institutions and organisations, such as marriage and the family, have links to individuals through social trajectories which change with life experiences and historical time (Elder, 1994). In particular it is thought that the association between parental separation and adult psychological distress will lessen over time (termed the 'reduced effect' hypothesis) through reducing stigma surrounding divorce, increasing availability of services (e.g. family mediation) and greater awareness of the importance of maintaining contact between children and both parents following separation (Ely, Richards, Wadsworth, \& Elliott, 1999).

There is some evidence to support this hypothesis, as the association between parental divorce and adult psychological health was found to be greater in studies conducted during the 1950s and 1960s (effect size $=-0.31$, $\mathrm{p}<0.001$ ), compared to studies from the 1980s (effect size $=-0.13, p<0.001$ ) (Amato \& Keith, 1991). However Ely and colleagues (1999) failed to support this hypothesis, not finding any change in the association between parental separation and children's educational attainment in their comparison of three British birth cohorts (born in 1946, 1958 and 1970).
Also Sigle-Rushton, Hobcraft, and Kiernan (2005) reported that the associations between parental divorce and adult psychological distress were similar in the 1958 and 1970 birth cohorts. Despite the lack of evidence for the 'reduced effect' hypothesis in the British birth cohorts, these and other studies have methodological limitations which may have affected the results and conclusions: for example, cohort differences in the association between parental divorce and adult outcomes were not statistically tested in some studies; only separations and divorces from midchildhood onwards were examined; and cases with missing values were dropped from the analyses. In this research note we aim to assess whether there is evidence for the 'reduced effect' hypothesis once these methodological problems have been addressed.

In addition it has been suggested that girls may be more affected by parental separation than boys, as girls are more likely to take on excessive responsibilities in the home, or emotionally support a parent (Hetherington \& Stanley-Hagan, 1999). Parental divorce has been found to be associated with an increase in adult affective disorders for women but not for men in some samples (see e.g. Rodgers, 1990), 
but knowledge regarding changes in gender differences in the association between separation and psychological distress over time is limited. We aim to extend current knowledge by including parental separation from birth in the study model; by statistically testing the 'reduced effect' hypothesis; by accounting for missing data; and by testing for possible gender differences in the association.

\section{Method}

\section{Data}

This study uses data from two of the British birth cohorts - the 1958 National Child Development Study (NCDS) and 1970 British Cohort Study (BCS) - which were also used by Ely et al. (1999) and Sigle-Rushton et al. (2005). The comparison of these two cohorts is particularly appropriate for this study: NCDS cohort members experienced relatively high levels of family stability as they grew up in the 1960s-1970s, sometimes referred to as the 'golden period' of marriage (Festy, 1980), when marriage occurred at young ages and amongst the vast majority of the population. Conversely, BCS cohort members grew up in a time of greater family instability, when societal divorce rates were increasing rapidly and the 'golden period' of marriage was in decline. These two studies are similarly designed, have large sample sizes, and contain directly comparable measures.

The NCDS was initially started as the Perinatal Mortality Study, recruiting 17,415 participants born in one week in 1958 in England, Wales, and Scotland (Shepherd, 1995). The participants' families were retraced in 1965 (age 7 years) and a longitudinal study initiated. Immigrants who were born in the same target week and who were identified by their schools were also added to the sample at ages 7,11 , and 16 years (total sample=18,558). Data has been collected from cohort member and parental interviews, medical examinations, teacher assessments, and school tests at birth, and at ages $7,11,16,23,33,42,46$, and 50 years. The BCS was started as the British Births
Survey recruiting 16,752 babies born in one week of 1970 (Elliott \& Shepherd, 2006). These children were retraced at age 5. Again, immigrants born during the same week were added to the sample in 1975 (age 5) and 1980 (age 10) - total sample $=18,732$. By 2008, BCS cohort members have been followed up at eight points across their lives (birth, age 5, 10, $16,26,30,34$, and 38 years). Our study uses data from the first six sweeps of both studies.

\section{Measures}

Parental separation was measured between the ages of 0-16 years. As this study was interested in the experience of parental separation, mother's marital status at birth was used to restrict the samples to those participants whose mothers were married or in a relationship at the time of the cohort member's birth: 17,887 in the NCDS $(96.4 \%$ of total sample including immigrants) and 17,467 in the BCS (93.2\%). Parental separation was derived from items detailing change in parental figures for each inter-sweep period, and reasons for this. If the reason was 'separation' or 'divorce', participants were coded as having experienced parental separation. If a reason of 'separation' or 'divorce' was given but the response to the parental figures question was missing, these people were also coded as having experienced parental separation.

Psychological distress was measured at age 33 (NCDS) and age 30 (BCS) using the Malaise Inventory (Rutter, Tizard, \& Whitmore, 1970). This is comprised of 24 items (yes/no responses) which cover emotional disturbance and somatic symptoms. Internal consistency of the scale is acceptable: Cronbach's $\alpha$ is 0.78 in the NCDS and 0.79 in the BCS. The total affirmative answers were summed giving a score out of 24 . This was dichotomised using the frequently-used cut-off point of 7 to indicate 'caseness' (Hope, Rodgers, \& Power, 1999; Sacker \& Cable, 2005).

Data were pooled across cohorts, and gender was taken from the birth sweep. $A$ priori confounding variables included in the analysis were mother's education, taken from 
the birth sweep of both cohorts $10=$ stayed in education beyond minimum age, $1=$ left education before or at minimum leaving age), mother's psychological distress (mother's psychiatric illness at age 11 in the NCDS and mother's Malaise Inventory score at age 10 in the BCS), and mother's age at the birth of the cohort member. Father's social class at the birth of the cohort member, coded according to the Registrar-General's scheme (see below), was included to control for selection effects, to account for the increased likelihood of parents from more disadvantaged backgrounds to separate. As both cohorts were initiated as medical studies, the Registrar-General's scheme is the only marker of social disadvantage available in both cohorts. This social class measure is based upon occupation and has the following categories: I (professional), II (managerial and technical), IIINM (skilled non-manual), IIIM (skilled manual), IV (semi-skilled manual) and $\mathrm{V}$ (unskilled).

\section{Statistical methods}

In order to go some way towards accounting for missing data, multiple imputation by chained equations (MICE) was conducted. This method is particularly useful in studies where missing values are present in many variables (Carpenter \& Plewis, 2011), as in these datasets. The performance of MICE is highly dependent upon the imputation model specified. The imputation model used here contained all analysis variables, variables predictive of missingness, and variables thought to be useful in providing information to fill in the gaps (indicators of health, such as reporting a limiting longstanding illness, and markers of social disadvantage, such as housing tenure and social class). Psychological distress was included in all imputations as its omission may result in bias (White, Royston, \& Wood, 2011). Following Von Hippel's (2007) method of multiple imputation then deletion, values for missing psychological distress scores were imputed using MICE, but only those participants with complete data on distress were used in the analysis. The final sample sizes for each cohort were: 10,923 in the NCDS and 10,714 in the BCS, representing those with complete data on psychological distress. Twenty datasets were imputed for each cohort and estimates given in the results section are those obtained by combining estimates across all data sets using Rubin's rules (1987). Table 1 shows the proportion of missingness within each analysis variable and also provides a comparison of observed and imputed data. The proportions for those with observed and imputed data are very similar, suggesting that the imputation has been suitably implemented.

The association between parental separation and adult psychological distress was tested using logistic regression. Likelihood ratio tests are often conducted in post-estimation hypothesis tests following logistic regression, but these are not appropriate for use with multiply-imputed data, as the estimates do not come from a single model and therefore the true likelihood is unknown (Medeiros, 2008). Wald tests are therefore recommended for use with multiply-imputed data (White, et al., 2011), and these were used to test both separation-gender and separation-cohort interactions. Analyses were adjusted for father's social class as a pre-separation risk factor, and for other confounders (mother's education, age and psychological distress). 
Evidence for the 'reduced effect' hypothesis

Table 1. \% missingness, and comparison of observed and imputed data in the NCDS and BCS

\section{NCDS}

\begin{tabular}{|c|c|c|c|c|c|c|c|c|}
\hline Variable & $\begin{array}{c}\text { Missingness } \\
\% \\
\end{array}$ & $\begin{array}{c}\text { Observed } \\
\text { data \% }\end{array}$ & $\begin{array}{l}\text { Imputed } \\
\text { data } \%\end{array}$ & $\begin{array}{l}\text { Imputed data: range of } \\
\text { participants (mean)* }\end{array}$ & $\begin{array}{c}\text { Missingness } \\
\% \\
\end{array}$ & $\begin{array}{c}\text { Observed } \\
\text { data \% }\end{array}$ & $\begin{array}{l}\text { Imputed } \\
\text { data } \%\end{array}$ & $\begin{array}{l}\text { Imputed data: range of } \\
\text { participants (mean)* }\end{array}$ \\
\hline \multicolumn{9}{|l|}{ Parental separation (0-16 yrs) } \\
\hline No & 28 & 91.2 & 90.9 & $9,893-9,972(9,926)$ & 52.9 & 80.9 & 79.6 & $8,481-8,575(8,529)$ \\
\hline Yes & & 8.8 & 9.1 & $951-1,030$ (997) & & 19.1 & 20.4 & $2,139-2,233(2,185)$ \\
\hline \multicolumn{9}{|l|}{ Psychological distress (30/33 yrs) } \\
\hline No & 0 & 93.2 & 93.2 & $10,183 * *$ & 0 & 87.4 & 87.4 & $9,359 * *$ \\
\hline Yes & & 6.8 & 6.8 & 740 & & 12.7 & 12.7 & 1,355 \\
\hline \multicolumn{9}{|l|}{ Gender (birth) } \\
\hline Male & 0 & 49.4 & 49.4 & 5,396 & 8.7 & 48.6 & 48.9 & $5,207-5,267(5,235)$ \\
\hline Female & & 50.6 & 50.6 & 5,527 & & 51.4 & 51.2 & $5,447-5,507(5,479)$ \\
\hline \multicolumn{9}{|l|}{ Confounders: } \\
\hline \multicolumn{9}{|l|}{ Father's social class (birth) } \\
\hline 1 & 7.1 & 4.7 & 4.8 & $508-532(519)$ & 9.2 & 5.4 & 5.4 & $569-596(580)$ \\
\hline II & & 13.8 & 13.8 & $1,487-1,520(1,506)$ & & 12.5 & 12.5 & $1,320-1,357(1,337)$ \\
\hline IIINM & & 10.2 & 10.2 & $1,102-1,135(1,117)$ & & 13.1 & 13.0 & $1,374-1,418(1,394)$ \\
\hline IIIM & & 50.8 & 50.8 & $5,512-5,562(5,545)$ & & 46.4 & 46.4 & 4,938-4,997 (4,969) \\
\hline IV & & 12.1 & 12.0 & $1,296-1,332(1,312)$ & & 14.1 & 14.1 & $1,485-1,517(1,507)$ \\
\hline $\mathrm{V}$ & & 8.4 & 8.5 & $900-936(925)$ & & 8.5 & 8.7 & 915-949 (927) \\
\hline \multicolumn{9}{|l|}{ Mother's education (birth) } \\
\hline Stayed beyond minimum age & 6.5 & 26.1 & 26.1 & $2,835-2,875(2,853)$ & 10.0 & 35.9 & 36.1 & $3,854-3,882(3,868)$ \\
\hline Left at or before minimum age & & 73.9 & 73.9 & $8,048-8,088(8,070)$ & & 64.1 & 63.9 & $6,832-6,860(6,846)$ \\
\hline \multicolumn{9}{|l|}{ Mother's age (birth) } \\
\hline Mean (range, standard deviation) & 5.1 & $\begin{array}{c}27.7(16- \\
47 \mathrm{yrs}, 5.6)\end{array}$ & $\begin{array}{c}27.7(16- \\
48 \mathrm{yrs}, 5.6)\end{array}$ & $27.65-27.72 * * *$ & 9.2 & $\begin{array}{c}26.2(16-50 \\
y r s, 5.3)\end{array}$ & $\begin{array}{c}26.2(16- \\
50 \mathrm{yrs}, 5.3)\end{array}$ & $26.16-26.21 * * *$ \\
\hline \multicolumn{9}{|c|}{ Mother's psychological distress (10/11 yrs) } \\
\hline Not distressed & 17.4 & 98.4 & 98.4 & $10,739-10,754(10,746)$ & 23.6 & 48.6 & 48.9 & $9,012-9,078(9,049)$ \\
\hline Distressed & & 1.6 & 1.6 & $169-184(177)$ & & 51.4 & 51.2 & $1,636-1,702(1,665)$ \\
\hline
\end{tabular}

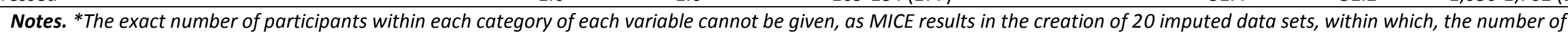

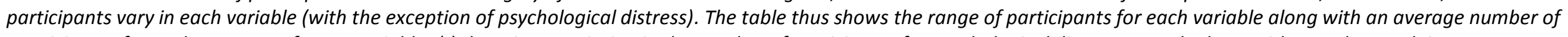

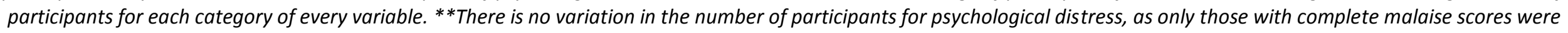
used in the analysis. ***Range of means of mother's age across imputed data sets. 


\section{Results}

The proportion of participants who experienced parental separation approximately doubled across the two cohorts; in the NCDS 9.1\% of participants experienced separation, but $20.4 \%$ did so in the BCS (Table 1 ). We tested the association between cohort and parental separation using logistic regression, and found an increased likelihood of experiencing separation in the BCS: taking the NCDS as the reference category, those in the BCS were approximately 2.6 times more likely to experience separation $(\mathrm{OR}=2.58,95 \% \mathrm{Cl}$ : $2.30,2.88, p<0.001)$.

Table 1 also shows that reporting of psychological distress was higher in the BCS compared to the NCDS. The majority of NCDS participants were from manual social classes; in the BCS there were relatively higher proportions of children born into non-manual social classes, though the majority were still born into manual social classes, particularly class IIIM. The proportion of mothers who stayed in education beyond the minimum school leaving age was higher in the BCS than the NCDS. There was a slight decrease in mother's age between the two cohorts. This study does not look at birth order and therefore this apparent decrease does not necessarily translate into a reducing age of women at childbearing. In the NCDS just $1.6 \%$ of mothers reported having been given a diagnosis of psychiatric illness. In the BCS the Rutter Malaise Inventory was completed by mothers when the children were aged 10 years, and the reported levels of psychological distress were relatively high (15.5\%). It should be noted that this figure would be expected to be higher than in the NCDS, as the Malaise Inventory does not just capture diagnosed psychiatric illness but also lower levels of psychological distress.

Table 2 shows the results of the adjusted logistic regression analysis. The interactions between parental separation and gender were not statistically significant (see results at bottom of Table 2), suggesting that the association between parental separation and psychological distress did not differ between men and women in either cohort. Consequently the rest of the analyses were conducted for both genders together. The results showed that despite the methodological issues we addressed (missing data, investigating parental separation between 0-16 years and statistically testing whether the association has changed over time), there was still no clear evidence that the association between parental separation and adult psychological distress had reduced over time $(p=0.69$ for the separationcohort interaction). Therefore our results suggest that in both cohorts, experiencing parental separation during childhood is associated with increased odds of reporting psychological distress in adulthood, after accounting for mother's education, age and psychological distress, and father's social class. 
Table 2. Results of logistic regression (OR $95 \% \mathrm{Cls}$ ) testing associations between parental separation and adult psychological distress, by cohort, adjusted for confounders (mother's education, age, psychological distress and father's social class)

\begin{tabular}{|c|c|c|c|c|}
\hline \multirow[t]{2}{*}{ Variable } & \multirow{2}{*}{$\begin{array}{l}1958 \text { NCDS } \\
\text { OR }(95 \% \mathrm{Cl})\end{array}$} & \multicolumn{3}{|c|}{1970 BCS } \\
\hline & & $P$ value & OR $(95 \% \mathrm{Cl})$ & $P$ value \\
\hline \multicolumn{5}{|l|}{ Parental separation (0-16 yrs) } \\
\hline No & Ref & & Ref & \\
\hline Yes & $1.75(1.35,2.26)$ & $<0.001$ & $1.52(1.26,1.83)$ & $<0.001$ \\
\hline \multicolumn{5}{|l|}{ Confounders: } \\
\hline \multicolumn{5}{|l|}{ Mother's education (birth) } \\
\hline Stayed after min. age & Ref & & Ref & \\
\hline Left at/before min. age & $1.56(1.25,1.94)$ & $<0.001$ & $1.16(1.01,1.33)$ & 0.037 \\
\hline \multicolumn{5}{|l|}{ Mother's age (birth) } \\
\hline Per 1 yr increase & $1.01(1.00,1.02)$ & 0.113 & $1.00(0.98,1.01)$ & 0.524 \\
\hline \multicolumn{5}{|l|}{ Mother's psychological distress (10/11 yrs) } \\
\hline No & Ref & & Ref & \\
\hline Yes & $1.19(0.70,2.04)$ & 0.524 & $1.63(1.39,1.91)$ & $<0.001$ \\
\hline \multicolumn{5}{|l|}{ Father's social class (birth) } \\
\hline 1 & $0.47(0.27,0.82)$ & $<0.001^{*}$ & $0.68(0.48,0.95)$ & $<0.001^{*}$ \\
\hline II & $0.58(0.42,0.78)$ & & $0.71(0.57,0.89)$ & \\
\hline IIINM & $0.79(0.59,1.05)$ & & $0.81(0.66,0.99)$ & \\
\hline IIIM & Ref & & Ref & \\
\hline IV & $1.15(0.91,1.44)$ & & $1.08(0.91,1.28)$ & \\
\hline $\mathrm{V}$ & $1.51(1.18,1.92)$ & & $1.13(0.92,1.39)$ & \\
\hline \multirow{3}{*}{$\begin{array}{l}\text { Total } \\
\text { Interaction between gender and separation } \\
\text { Interaction between cohort and separation }\end{array}$} & $N=10,923$ & & $N=10,714$ & \\
\hline & $0.71(0.44,1.14)$ & 0.13 & $0.92(0.68,1.24)$ & 0.51 \\
\hline & \multicolumn{3}{|c|}{ OR $=0.89(0.64,1.25)$} & 0.69 \\
\hline
\end{tabular}

Note. *P value for trend given 


\section{Discussion}

In this study we found that parental separation, occurring during childhood, was associated with increased odds of reporting psychological distress in adulthood in two British birth cohorts, supporting results from many previous studies which suggest that parental separation is associated with depression and anxiety in adult life (e.g. Amato, 1991; Kendler et al., 2002). We found this association despite making some methodological improvements on existing work. It has been suggested that parental separation is associated with the increased reporting of psychological distress in adulthood through pathways of increased disadvantage relative to those from 'intact' families (Wadsworth, Maclean, Kuh, \& Rodgers, 1990), including reduced educational attainment (e.g. Ross \& Mirowsky, 1999), poorer parent-child relationships (Amato \& Sobolewski, 2001), and the inter-generational transmission of divorce (Dronkers \& Härkönen, 2008).

The results of this study do not, however, support the 'reduced effect' hypothesis, and thus confirm earlier findings based upon complete case analyses in these cohorts (Ely et al., 1999; Sigle-Rushton et al., 2005). The findings suggest that the association of parental separation with the psychological health of offspring has not reduced, but that as societal divorce rates have increased substantially over this period, more people have been affected. It is conceivable that a 'reduced effect' is counteracted by social changes such as increasing relative financial hardship and changing attitudes towards divorce, that act in opposite directions (Ely et al., 1999).

With regards to gender it was thought that the association between parental separation and adult psychological distress would be greater for women than men, as the inconsistent past evidence on this issue appeared to lean in this direction (Hetherington \& Stanley-Hagan, 1999; Pirkola et al., 2005). In this study, however, there was no evidence of differential associations for men and women, supporting previous findings of a lack of gender differences (Amato, 1991; Amato \& Booth, 1991; Amato \& Keith, 1991; Amato \& Sobolewski, 2001; Kendler et al., 2002; Kessler, Davis, \& Kendler, 1997; Rodgers, Power, \& Hope, 1997; Wallerstein, 1991; Zill, Morrison \& Coiro, 1993). It has been shown that girls are more likely to emotionally support a parent, but that boys are more likely to witness conflict (Hetherington \& Stanley-Hagan, 1999), and it is possible that pathways linking parental separation to adult psychological distress are different for men and women.

Despite the methodological improvements we made on previous work, the findings of this study need to be interpreted in light of a number of limitations. First, it is possible that participants in the earlier cohort were more likely to experience parental remarriage or repartnership following separation, due to the increased stigma of single parenthood at the time, which may have buffered the effect of parental separation upon the child's psychological health to some extent. Second, it has been shown in some studies that it is the conflict surrounding relationship breakdown that is responsible for poorer psychological health outcomes in children (Amato, Loomis, \& Booth, 1995; Cummings \& Davies, 2002). Unfortunately in these studies there are insufficient measures of partnership quality and family conflict to investigate this. In addition it is possible that there may have been a substantial lag time between the sharp increase in divorce rates in the early 1970s and any reducing effect upon children, which the 1970 BCS data was not able to capture. It is therefore possible that if a later cohort were studied, a reduced association might be seen.

There are several major strengths of this study. The first is that information on both parental separation and confounders was collected prospectively, minimising the risk of recall bias. The study used data from two large- 
scale longitudinal birth cohorts designed to be representative of the British population of similar ages, which are particularly appropriate for testing these hypotheses. The third advantage is that missing values were not ignored, as they are in many studies, but rather dealt with by multiple imputation methods appropriate under the assumption of missing at random (MAR). It is possible that this assumption does not entirely hold, but it is likely to be more plausible than the assumption that data are missing completely at random (MCAR) - the assumption underlying complete case analyses. Imputation adds power to the analyses while reducing the risk of bias due to selective attrition.

The findings of this study add support to the evidence base addressing the relationship between exposure to parental separation in childhood and psychological distress in adult life. The finding that the association between parental separation and psychological distress has not reduced over time, despite parental separation becoming more common, highlights a real need to support families undergoing problems in order to reduce the impact on children's long-term psychological health.

\section{Acknowledgements}

This study was supported by the Economic and Social Research Council grant RES-596-28-001 (ESRC International Centre for Life Course Studies in Society and Health). Thanks to all participants of the National Child Development Study and British Birth Cohort and to the study teams. Thanks to the UK Data Archive for providing access to the data.

\section{References}

Amato, P. (1991). Parental absence during childhood and depression in later life. The Sociological Quarterly, $32,543-556$.

Amato, P., \& Booth, A. (1991). Consequences of parental divorce and marital unhappiness for adult wellbeing. Social Forces, 69, 895-914.

Amato, P., \& Keith, B. (1991). Parental divorce and adult well-being: a meta-analysis. Journal of Marriage and the Family, 53, 43-58.

Amato, P., Loomis, L., \& Booth, A. (1995). Parental divorce, marital conflict and offspring well-being during early adulthood. Social Forces, 73, 895-915.

Amato, P., \& Sobolewski, J. (2001). The effects of divorce and marital discord on adult children's psychological well-being. American Sociological Review, 66, 900-921.

Carpenter, J., \& Plewis, I. (2011). Analysing longitudinal studies with non-response: issues and statistical methods. In M. Williams \& P. Vogt (Eds.), The SAGE handbook of innovation in social research methods (pp. 498-523). London: SAGE publications.

Chase-Lansdale, P., Cherlin, A., \& Kiernan, K. (1995). The long-term effects of parental divorce on the mental health of young adults: a developmental perspective. Child Development, 66, 1614-1634.

Cummings, E., \& Davies, P. (2002). Effects of marital conflict on children: recent advances and emerging themes in process-oriented research. Journal of Child Psychology and Psychiatry, 43, 31-63.

Dronkers, J., \& Härkönen, J. (2008). The intergenerational transmission of divorce in cross-national perspective: results from the fertility and family surveys. Population Studies, 62, 273-288.

Elder, G. (1994). Time, human agency, and social change. Social Psychology Quarterly, 57, 4-15.

Elliott, B., \& Shepherd, P. (2006). Cohort profile: 1970 British birth cohort. International Journal of Epidemiology, 35, 836-843.

Ely, M., Richards, M., Wadsworth, M., \& Elliott, B. (1999). Secular changes in the association of parental divorce and children's educational attainment - evidence from three British birth cohorts. Journal of Social Policy, 28, 437-455.

Festy, P. (1980). On the context of marriage in Western Europe. Population and Development Review, 6, 311315.

Hetherington, E., \& Stanley-Hagan, M. (1999). The adjustment of children with divorced parents: a risk and resiliency perspective. Journal of Child Psychology and Psychiatry, 40, 129-140.

Hope, S., Rodgers, B. \& Power, C. (1999). Does financial hardship account for elevated psychological distress in lone mothers? Social Science and Medicine, 49, 1637-1649. 
Kendler, K., Shether, K., Garner, C., \& Prescott, C. (2002). Childhood parental loss and risk for first-onset of major depression and alcohol dependence: the time-decay of risk and sex differences. Psychological Medicine, 32, 1187-1194.

Kessler, R., Davis, C., \& Kendler, K. (1997). Childhood adversity and adult psychiatric disorder in the US National Comorbidity Survey. Psychological Medicine, 27, 1101-1119.

Kuh, D., \& Maclean, M. (1990). Women's childhood experience of parental separation and their subsequent health and socioeconomic status in adulthood. Journal of Biosocial Science, 22, 121-135.

Medeiros, R. (2008). Likelihood ratio tests for multiply imputed datasets. In 2008 Fall North America STATA users group meeting.

Office for National Statistics (2006). Divorces: 1858-2003, number of couples divorcing, by party petitioning/granted decree.

Office for National Statistics (2010). Marriage, divorce and adoption statistics, England and Wales (Series FM2), No. 35.

Pirkola, S., Isometsä, E., Aro, H., Kestilä, L., Hämäläinen, J., Veijola, J., Kiviruusu, O., \& Lönnqvist, J. (2005). Childhood adversities as risk factors for adult mental disorders. Social Psychiatry and Psychiatric Epidemiology, 40, 769-777.

Rodgers, B. (1990). Adult affective disorder and early environment. British Journal of Psychiatry, 157, 539550.

Rodgers, B., Power, C,. \& Hope, S. (1997). Parental divorce and adult psychological distress: evidence from a national birth cohort: a research note. Journal of Child Psychology and Psychiatry, 38, 867-872.

Rodgers, B. \& Pryor, J. (1998) Divorce and separation: the outcomes for children. York: Joseph Rowntree Foundation.

Ross, C., \& Mirowsky, J. (1999). Parental divorce, life-course disruption and adult depression. Journal of Marriage and the Family, 61, 1034-1045.

Rubin, D. (1987). Multiple imputation for non response in surveys. New York: J. Wiley \& Sons.

Rutter, M., Tizard, J., \& Whitmore, K. (1970). Education, health and behaviour. London: Longmans.

Sacker, A., \& Cable, N. (2005). Do adolescent leisure-time physical activities foster health and well-being in adulthood? Evidence from two British birth cohorts. European Journal of Public Health, 16, 331-335

Shepherd, P. (1995). The National Child Development Study - an introduction to the origins of the study and the methods of data collection. London: Social Statistics Unit, City University. Published May 1995 [accessed 23 March 2009]. Retrieved from: http://www.cls.ioe.ac.uk/studies.asp?section $=0001000200030004$

Sigle-Rushton, W., Hobcraft, J., \& Kiernan, K. (2005). Parental divorce and subsequent disadvantage: a crosscohort comparison. Demography, 42, 427-446.

Von Hippel, P. (2007). Regression with missing Ys: an improved strategy for analysing multiply imputed data. Sociological Methodology, 37, 83-117.

Wadsworth, M., Maclean, M., Kuh, D., \& Rodgers, B (1990). Children of divorced and separated parents: summary and review of findings from a long-term follow-up study in the UK. Family Practice, 7, 104109.

Wallerstein, J. (1991). The long-term effects of divorce on children: a review. Journal of American Academy of Child and Adolescent Psychiatry, 30, 349-360.

White, I., Royston, P., \& Wood, A. (2011). Multiple imputation using chained equations: issues and guidance for practice. Statistics in Medicine, 30, 377-399.

Zill, N., Morrison, D., \& Coiro, M. (1993). Long-term effects of parental divorce on parent-child relationships, adjustment and achievement in young adulthood. Journal of Family Psychology, 7, 91-103. 